\title{
Effect of the Incorporation of Micro and Nanocellulose Particles on the Anticorrosive Properties of Epoxy Coatings Applied on Carbon Steel
}

\author{
Cleide Borsoi ${ }^{\star *}{ }^{\circledR}$, Lisete Cristine Scienza ${ }^{b}$, Ademir José Zattera $^{c}$, Carlos Arthur Ferreira ${ }^{d}$ \\ ${ }^{a}$ Centro de Ciências Exatas e Tecnológicas, Universidade do Vale do Taquari (UNIVATES), 95914-014, \\ Lajeado, RS, Brasil \\ ${ }^{b}$ Departamento de Materiais, Escola de Engenharia, Universidade Federal do Rio Grande do Sul, \\ 91509-900, Porto Alegre, RS, Brasil \\ cPrograma de Pós-Graduação em Engenharia de Processos e Tecnologias (PGEPROTEC), \\ Universidade de Caxias do Sul, Caxias do Sul, RS, Brasil \\ ${ }^{d}$ Laboratório de Materiais Poliméricos (LAPOL), Programa de Pós-Graduação em Engenharia de \\ Minas, Metalúrgica e de Materiais (PPGE3M), Universidade Federal do Rio Grande do Sul, Caixa \\ Postal 15010, 91501-970, Porto Alegre, RS, Brasil
}

Received: March 09, 2017; Revised: July 25, 2018; Accepted: September 28, 2018

\begin{abstract}
Polymeric coatings may act as a physical barrier between the aggressive ions and the metal substrate. However, prolonged exposure may cause damage to the polymer coating, leading to a continuous reduction of the barrier effect and consequently loss of the corrosion protection. The objective of this study is to determine the effect of aminopropyltriethoxysilane (APS), cellulose and polyaniline emeraldine-salt (PAni ES) in an epoxy coating on the corrosion protection of mild steel. Microcrystalline cellulose $(\mathrm{MCC})$ and cellulose nanowhiskers $(\mathrm{CNW})$ functionalized or not with PAni ES were used and compared. The coating properties were investigated by electrochemical impedance spectroscopy (EIS), salt spray test and scanning electron microscopy (SEM). The surface of the carbon steel, after $1000 \mathrm{~h}$ of exposure, did not present evidence of superficial corrosion. Polymer coatings using CNW and PAni ES showed improved corrosion protection properties even after 90 days of immersion in $3.5 \mathrm{wt} \% \mathrm{NaCl}$ solution. The greatest increase in the corrosion resistance of the coating was found by EIS for the epoxy coating reinforced with CNW functionalized with PAni ES, revealing a synergistic effect of the electroactivity of a conducting polymer and nanosized cellulose particles.
\end{abstract}

Keywords: cellulose nanowhiskers, microcrystalline cellulose, polyaniline, polymeric coatings, electrochemical impedance spectroscopy.

\section{Introduction}

Polymeric coatings are widely used as a common, practical and cost-effective method to protect metal surfaces from environment action. The corrosion performance of polymeric coatings depends upon several parameters such as adhesion to the metal substrate, permeability, thickness, chemical and mechanical resistance in aggressive environments. Thus, additionally to the properties of the coatings, the metal pretreatment before their application represents an important role on the corrosion performance and must be carefully conducted to provide effective protection.

Conversion coatings are widely used in surface treatments before the application of polymeric coatings to enhance adhesion between the metal substrate and the coating. The classic pretreatments that use chromium or phosphate have been replaced by systems that generate less waste and do not use toxic materials ${ }^{1-3}$. The use of zirconium conversion coating showed environmental and economic benefits since the layer is free of heavy metals, phosphates and volatile compounds ${ }^{2}$. By using zirconium conversion coatings, sludge and cleaning baths are reduced, thus lessening the generation of effluents. In addition, these coatings require a shorter operation time than other conventional treatments ${ }^{4}$.

The corrosion resistance is improved in the treated and painted metal surface due to the barrier effect created by the polymeric coating between the metal and the corrosion media. Thus, epoxy resins are considered important mainly due to chemical, abrasion and impact resistance, electrical insulating properties and good adhesion to metal substrates ${ }^{5-7}$. Although acting primarily by barrier effect, these coatings may be permeable to water, oxygen and corrosive ions such as $\mathrm{Cl}^{-}, \mathrm{H}^{+}$and $\mathrm{SO}_{4}^{2-}$. Protective properties of epoxy coatings can be improved if special compounds and fillers are used as corrosion inhibitors to formulate anticorrosive primers for metallic substrates. As many of these substances are considered to be toxic and ecologically unsafe, the search for new alternative compounds and fillers is under way. Organofunctionalsilanes, cellulose fibers and intrinsically conductive polymers (ICPs) have emerged recently as alternative chromate and phosphate treatments for metals. When they are used alone or in associate form, they are able

*e-mail: eng.cleide@yahoo.com.br 
to provide a synergistic effect to corrosion protection and other properties of organic coatings ${ }^{8,9}$.

Silanes are hybrid organic-inorganic compounds widely used in composite materials as filler/matrix coupling agents. When embedded in epoxy based resins, silanes undergo hydrolysis forming silanol $(\mathrm{Si}-\mathrm{OH})$ that enhances the chemical structure acting as initiator of a crosslinking process, increasing resistance to permeation of ions that are aggressive to polymer coatings. Additionally, silane acts to promote chemical bonding between the polymeric coating and the metal substrate through the formation of covalent bonds like Si-O-metal ${ }^{10}$. Silane groups compatible with the epoxy resin can participate in the curing process by promoting better physical-mechanical properties, thermal stability, anticorrosion characteristics, flexibility, toughness, durability and easy processing ${ }^{11}$. The main disadvantage of using silane is that the substrate must bear hydroxyl groups on its surface and the short shelf life of the silane solutions.

Conductive polymers have been the center of attention in the past several years due to their electrochemical properties and their mixed ionic/electronic conductivity properties and they have been used as host matrices in various composite films ${ }^{12}$. Some specific ICPs that enhance corrosion resistance are polyaniline, polythiophene and polypyrrole ${ }^{13}$. Concerning polyaniline, its role in the protection against corrosion is usually associated with its redox catalytic effect, which provides the formation of a stable oxide layer on the metallic substrate. This layer can act as a barrier preventing the passage of oxygen, hydrogen, water, and other aggressive ions to the metal surface ${ }^{12,14,15}$.

Although PAni shows poor mechanical properties, after the incorporation of micro or nanoparticles such properties are improved, making it an alternative to obtain conductive nanofillers with superior mechanical properties ${ }^{7}$. A great shift in the use of nanofillers from natural resources is happening mainly to introduce an eco-friendly character in the resulting composites. The extended chain conformation and microfibrillar morphology of cellulose results in significant load carrying capability. Micro and nanofibers of cellulose present a great potential of applications, since they present high aspect ratio, high crystallinity and mechanical properties ${ }^{7,16,17}$. The nanocellulose has superior mechanical properties in comparison to microcellulose, becoming more interesting to be used as reinforcing filler in a polymeric matrix ${ }^{18}$. In addition it includes important properties of cellulose as: low density, biodegradability and the fact it comes from renewable sources ${ }^{19}$

Several studies have been carried out in order to obtain cellulose/PAni composites in which cellulose-based materials (derived from various sources) are incorporated into PAni ${ }^{20-22}$. Cellulose/polyaniline composites combine the mechanical properties of the pulp (in the form of micro- or nanoparticles) and the conductivity of PAni. These composites can be applied in anticorrosion coatings, conductive adhesives, antistatic material and electromagnetic shielding and smart biosensors ${ }^{23}$. Even at low concentrations, nanoparticulate dispersions of cellulose/polyaniline in various paints are expected to be able to promote a complex ultra fine network that enhances the corrosion protection properties of the coatings.

Loung et al. ${ }^{22}$ have obtained composites of cellulose nanofibers modified with 5 to $80 \mathrm{wt} \%$ PAni to obtain paper with high electrical conductivity and good mechanical properties, which can be applied in flexible electrodes, sensors and other devices. Borsoi et al. ${ }^{24}$ found that epoxy coatings based on cellulose nanowhiskers functionalized with PAni showed improved flexibility and adhesion properties and they could be considered as protective coatings for carbon steel.

In our previous work ${ }^{24}$ celulose nanowhiskers were successfully functionalized with PAni ES and incorporated in an epoxy resin to achieve a coating with superior adhesion and flexibility properties. In the continuity of that study, the present work aimed to determine the effect of APS, cellulose and PAni ES in an epoxy coating on the corrosion protection of mild steel. MCC and CNW functionalized or not with PAni ES were used and compared. The obained coatings were applied on zirconium conversion coating pretreated carbon steel panels and their corrosion performance was evaluated through electrochemical impedance spectroscopy (EIS) and salt spray chamber test in neutral sodium chloride media.

\section{Materials and Methods}

\subsection{Materials}

MCC was provided by Sigma-Aldrich and CNW was obtained from MCC by a mechanical high friction grinding process. Epoxy resin was supplied by Huntsman (Araldite GZ 488N40-1) being a monocomponent epoxy in methyl ethyl ketone solvent (Synth). A solution was prepared with pure aniline (Sigma-Aldrich), 98\% ammonium persulfate (Vetec) and hydrochloric acid (F. Maia Industry and Trade Ltd.) $(36.5 \%)$ for the functionalization of MCC and CNW with PAni. The coatings were applied on carbon steel with the following composition: $0.062 \mathrm{wt} \% \mathrm{C} ;<0.0100 \mathrm{wt} \%$ $\mathrm{Si} ; 0.333 \mathrm{wt} \% \mathrm{Mn} ; 0.002 \mathrm{wt} \% \mathrm{P} ; 0.006 \mathrm{wt} \% \mathrm{~S}$ and 99.587 $\mathrm{wt} \% \mathrm{Fe}$. The zirconium conversion coating was obtained by using hexafluorozirconic acid (Nanotex ZR 16) provided by Klintex Petrochemicals Industrial Ltda. The silane used was aminopropyltriethoxysilane (APS) (Sigma-Aldrich).

\subsection{Preparation of $C N W$}

MCC was ground in a super mass colloider (MKCA6-2 Masuko Sanguo, Japan). A suspension containing $4.5 \mathrm{wt} \%$ MCC in distilled water was ground for 150 scans with a rotation of $2500 \mathrm{rpm}$ and grinding area set to contact mode (gap between the plates adjusted to zero). The pulp (cellulose + water) passes between a static and a rotating stone in which the nanofibers that make up the fiber structure are individualized 
and the water was removed by lyophilization process (Liotop, model L101). The resulting CNW was ground using a bench grinder (Cadence, model MDR301) and classified using 400 mesh Tyler sieve to remove agglomerates.

\subsection{Functionalization of MCC and $C N W$ with PAni ES}

Functionalization of cellulose (MCC or CNW) with PAni ES (emeraldine salt - PAni in the conductive form) was obtained using $3 \mathrm{~g}$ of aniline in a $100 \mathrm{~mL}$ solution of $1 \mathrm{~mol} . \mathrm{L}^{-1} \mathrm{HCl}$. This solution was added to $3 \mathrm{~g}$ of $\mathrm{MCC}$ or $\mathrm{CNW}$ under magnetic stirring at $5 \pm 2{ }^{\circ} \mathrm{C}$ for $30 \mathrm{~min}$. Polymerization was initiated by the addition of a precooled solution of ammonium persulfate (AP) (4.5 g dissolved in $45 \mathrm{~mL}$ of $1 \mathrm{~mol} . \mathrm{L}^{-1} \mathrm{HCl}$ solution) which remained in the ice bath for $1 \mathrm{~h}$ and under stirring at room temperature for $18 \mathrm{~h}$. The dark green precipitate was filtered and washed with ethanol and distilled water until clean. The sample was dried in an oven for $24 \mathrm{~h}$ at $70^{\circ} \mathrm{C}$, ground in a bench grinder (Cadence, MDR301) and stored in a desiccator until use. Figure 1 shows the scheme of functionalization of cellulose with PAni ES.

\subsection{Pretreatment of the substrate, preparation and application of the coating}

Carbon steel panels sized $120 \mathrm{~mm}$ x $70 \mathrm{~mm} \times 0.75 \mathrm{~mm}$ were previously washed with ethanol, abraded with emery paper, and finally subjected to alkaline degreasing in a 5 wt\% Saloclean 679 (Klintex Insumos Industriais Ltda) solution for $10 \mathrm{~min}$ at $70^{\circ} \mathrm{C}$, followed by washing in water and drying with cold air. Afterwards, the conversion coating on the metal substrate was obtained by immersion in a 2.7 $\mathrm{wt} \%$ hexafluorozirconic acid solution for $40 \mathrm{~s}$ at $25 \pm 5^{\circ} \mathrm{C}$ and dried in an oven for $10 \mathrm{~min}$ at $110^{\circ} \mathrm{C}$.

The cellulose samples (MCC and $\mathrm{CNW}$ ) previously dried at $80^{\circ} \mathrm{C}$ for $12 \mathrm{~h}$ were added to the epoxy resin with $3 \mathrm{wt} \%$ APS. This mixture was held in a mechanical stirrer with cowles type disk propellers at $2500 \mathrm{rpm}$ for $10 \mathrm{~min}$. The polymeric coatings were applied by dragging using a bar on film applicator and dried in an oven for $2 \mathrm{~h}$ at $140^{\circ} \mathrm{C}$. The final average thickness of the coatings was $95.8 \pm 7.2 \mu \mathrm{m}$. The nomenclature and composition of the polymer coatings are described in Table 1.

\subsection{Characterization}

The electrochemical behavior was studied by Electrochemical Impedance Spectroscopy (EIS) measurements performed in a BI-AUTOLAB 302 Potentiostat with an impedance module (from EcoChemie $\AA$ ), scanning at a frequency range between $10^{5} \mathrm{~Hz}$ and $10^{-1} \mathrm{~Hz}$ with a sinusoidal perturbation amplitude of $10 \mathrm{mV}$. All measurements were conducted with a three-electrode arrangement, without agitation of the electrolyte at a room temperature and in aerated conditions: the working electrode was the coated steel sample with an exposed area (circular shape) of $0.785 \mathrm{~cm}^{2}$, the reference and the counter-electrode were a saturated calomel electrode (SCE) and a platinum coil with large area, respectively. The electrochemical cell was inserted in a Faraday cage to avoid the effect of external static electric fields. The impedance measurements were performed in $3.5 \mathrm{wt} \% \mathrm{NaCl}$ electrolyte, at the open circuit potential (OCP) after 30 and 90 days of immersion. For all samples 5 min immersion time was

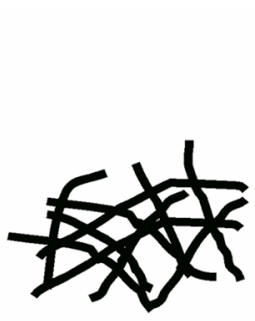

CNW

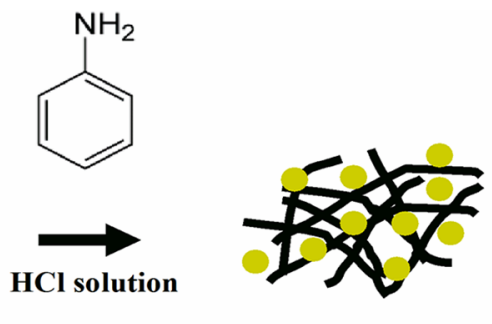

$\mathrm{CNW}+$ aniline in HCl solution
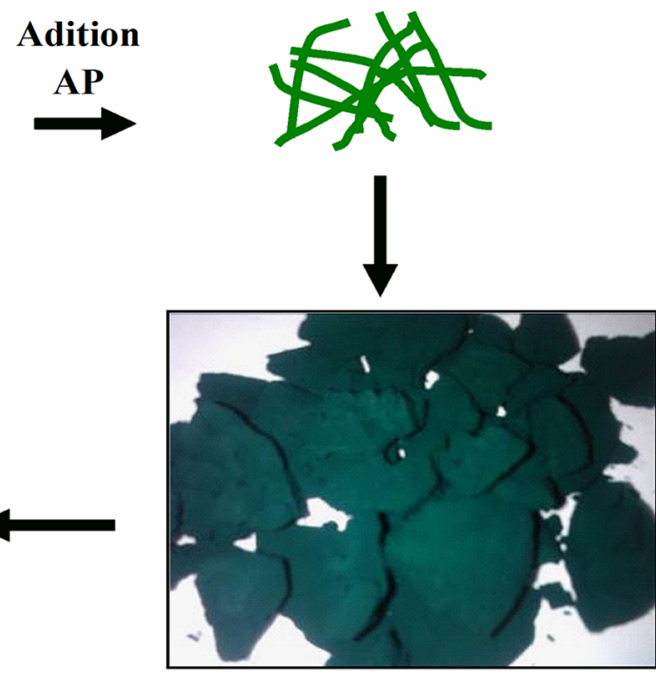

CNW/PAni SE after

\section{Reaction between the cellulose and PAni}

filtration of vácuo

Figure 1. Scheme of the preparation of MCC or CNW functionalized with PAni ES. 
Table 1. Identification and composition of the polymeric coatings.

\begin{tabular}{|c|c|c|c|c|c|c|}
\hline Sample & $\begin{array}{l}\text { Epoxy } \\
\left(w t^{0} \%\right)\end{array}$ & $\begin{array}{l}\mathrm{MCC} \\
(\mathrm{wt} \%)\end{array}$ & $\begin{array}{c}\text { MCC PAni ES } \\
(w t \%)\end{array}$ & $\begin{array}{l}\text { CNW } \\
(\mathrm{wt} \%)\end{array}$ & $\begin{array}{c}\text { CNW PAni ES } \\
(w t \%)\end{array}$ & $\begin{array}{l}\text { APS } \\
\left(w t^{0} \%\right)\end{array}$ \\
\hline RE APS - Zr & 97 & - & - & - & - & 3 \\
\hline $\mathrm{RE}$ APS/MCC - Zr & 94 & 3 & - & - & - & 3 \\
\hline RE APS/CNW - Zr & 94 & - & - & 3 & - & 3 \\
\hline RE APS/MCC PAni ES - Zr & 94 & - & 3 & - & - & 3 \\
\hline RE APS/CNW PAni ES - Zr & 94 & - & - & - & 3 & 3 \\
\hline
\end{tabular}

RE - Epoxy resin; MCC - microcrystalline cellulose; CNW - cellulose nanowhiskers; PAni ES - polyaniline in emeraldine salt form; APS - aminopropyltriethoxysilane; $\mathrm{Zr}$ - zirconium conversion coating.

maintained to stabilize the open circuit potential before starting the electrochemical impedance measurements. In order to verify reproducibility, at least two samples were tested.

The salt spray test was conducted according to ASTM B117 in a Bass Equipment chamber model USX-6000/2009. A neutral (pH 6.8-7.2) salt-water solution containing $5 \mathrm{wt} \%$ $\mathrm{NaCl}$ was continuously sprayed in a closed testing chamber at $35 \pm 2^{\circ} \mathrm{C}$. The edges of the panels were protected with beeswax and put in supports to ensure the default position for the samples placement between 15 and $30^{\circ}$ from the vertical. In order to evaluate the subcutaneous migration according to ASTM D1654 after exposure, an " $X$ " shaped incision was performed on the coating surface before submitting to salt spray test for $1000 \mathrm{~h}$. The test was performed in triplicate for each coating.

The morphology and chemical composition of the substrates were analyzed by Scanning Electron Microscopy with Field Emission (FESEM) using a Tescan model Mira 3 microscope with an Energy Dispersive Spectroscopy (EDS) detector and an acceleration voltage of $15 \mathrm{kV}$. The surfaces were coated with a thin gold layer prior to analysis.

\section{Results and Discussion}

Figure 2 shows the Nyquist complex plane plots for 30 and 90 days of immersion in $3.5 \mathrm{wt} \% \mathrm{NaCl}$ solution. The electrochemical response for the RE APS-Zr coating (Figure 2a) did not represent a true capacitor and the characteristic semicircle was suppressed in the Nyquist plot.

The RE APS/MCC-Zr coating (Figure 2b) showed complete formation of the capacitive arc after 30 days of immersion. This means that diffusion of the corrosive electrolyte occurs at the coating/metal interface with a very short immersion time. The formation of a second semicircle at low frequencies suggests that electrochemical reactions at the coating/metal interface progress due to the electrolyte access to the metal substrate ${ }^{25,26}$. The increase in polarization resistance ( $\mathrm{Rp}$ ) of coating after 90 days of exposure suggests that the pores within the coating layer were blocked with corrosion products, and the ionic movement in the coating layer was shortly disrupted ${ }^{25-27}$. For the RE APS/CNW-Zr coating (Figure 2d), Rp decreases with increasing electrolyte exposure time due to the penetration of aggressive ions and water through the coating.

The presence of PAni in coatings has profound effects on their protective performance. The values of overall impedances in systems with PAni ES are much higher in order of magnitude when RE APS/MCC-Zr and RE APS/CNW-Zr are compared with the systems containing PAni ES during exposure to $3 \mathrm{wt} \% \mathrm{NaCl}$ solution. After 90 days, systems with epoxy coatings with PAni ES showed increased protective properties (Figure 2c and 2e), thus indicating the possibility that PAni ES is respondible for enhancing barrier properties, forming a redox pair in which the conducting polymer is reduced oxidizing the metal, thus forming a passive oxide layer ${ }^{27}$. PAni is small sized and can be dispersed uniformly in the coating matrix and intertwined with each other to form a dense network, which results in a good continuity of distribution of PAni. As a result, a dense passive layer is formed on the surface to protect the metal beneath the oxide layer from further corrosive attack ${ }^{28}$.

Therefore, the improved corrosion protection suggests two possible mechanisms. The first can be related to the formation of a larger number of van der Waals forces and hydrogen bonding between PAni ES and cellulose in addition to the excellent adhesion of the polymeric coating to the metal substrate provided by silane and zirconium conversion coating, which acts in the final crosslinking of the epoxy chains and the amino groups provided by APS. The nanoparticles improved the adherence of the cured epoxy coating to the underlying substrate and altered the physiochemical properties of the coating-steel interface. The second indicates that the ions have a zigzag-shaped path, resulting in an increase in the diffusion path due to the presence of nanoparticles leading to an improved barrier performance of the epoxy coating (Figure 3). A similar behavior was observed by Shi et al. ${ }^{29}$, who evaluated the influence of nanoparticles of $\mathrm{SiO}_{2}, \mathrm{Zn}$, $\mathrm{Fe}_{2} \mathrm{O}_{3}$ and halloysite clay in epoxy coatings, and also by Conradi et al. ${ }^{30}$, who investigated the influence of silica nanoparticles in epoxy coatings.

A more detailed interpretation of the EIS measurements was performed by fitting the experimental plots (Figure 4) in equivalent electrical circuit models to simulate the electrochemical behavior of the studied coatings. The values 

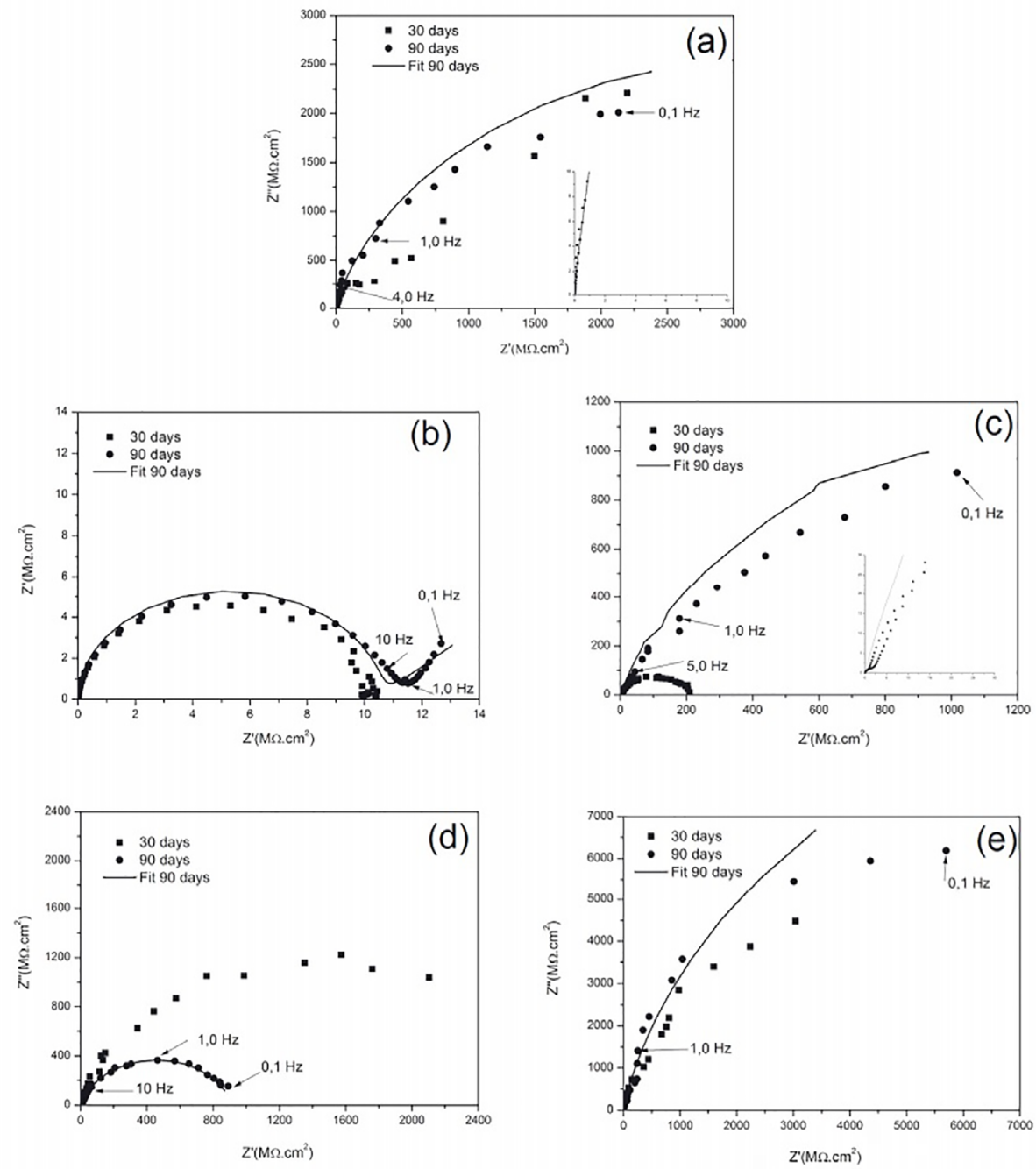

Figure 2. Nyquist diagram for polymer coatings (a) RE APS - Zr, (b) RE APS/MCC - Zr, (c) RE APS/MCC PAni ES - Zr, (d) RE APS/CNW - Zr and (e) RE APS/CNW PAni ES - Zr after immersion for 30 and 90 days in $3.5 \mathrm{wt} \% \mathrm{NaCl}$ solution.

$$
\mathrm{H}_{2} \mathrm{O}, \mathrm{Cl}, \mathrm{O}_{2}
$$

(a)

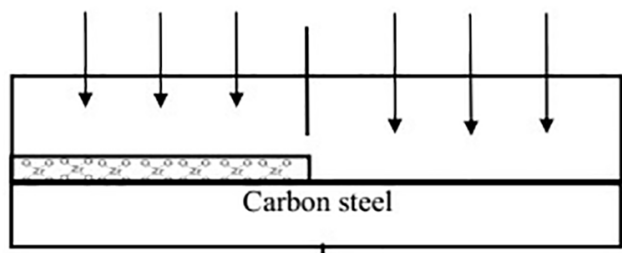

(b)

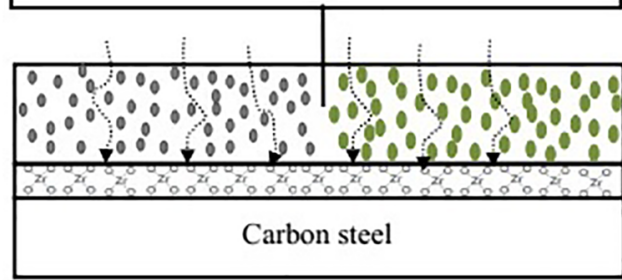

- CNW PAni ES

\section{- $\mathrm{CNW}$}

Figure 3. Representation of the diffusion of the aggressive agents in the polymer coating (a) without $\mathrm{CNW}$, with $\mathrm{Zr}$ conversion coating in steel (left) and without $\mathrm{Zr}$ conversion coating (right) and (b) with CNW (left) and CNW / PAni ES (Right). of different parameters obtained from the fitted Nyquist plots are represented in Table 2. These results are related to the interaction of the electrolyte with the film, such as its permeation through the film, which is not an instantaneous process. The equivalent circuit shown in Figure 4 describes the electrode coated with a porous layer which contains two interfaces: coating/electrolyte and coating/metal. Where $\mathrm{R}_{\mathrm{s}}$ is the electrolyte resistance, $\mathrm{R}_{\mathrm{c}}$ is the resistance of the coating at high frequencies, $R_{p}$ is the polarization resistance at the coating/metal interface observed at lower frequencies, $\mathrm{C}_{\mathrm{c}}$ is the capacitance of the coating and $\mathrm{Q}$ is the charge accumulation at the electrolyte /polymer interface in the inner regions of the electrode, which is also affected by the decreased conductivity of the electrolyte, represented by the constant phase element (CPE). The CPE element is associated with the $\mathrm{n}$ parameter describing an ideal capacitor for $\mathrm{n}=1$, ideal resistor for $\mathrm{n}=0$ and a CPE $0<\mathrm{n}<1$ due to the heterogeneity of the system. 


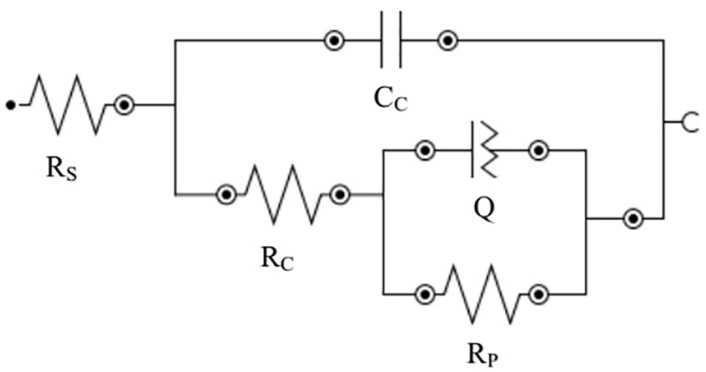

Figure 4. Equivalent electrical circuit to fit the results obtained after 90 days of immersion in $3.5 \mathrm{wt} \% \mathrm{NaCl}$ solution.

Coatings based on MCC and PAni ES did not show improvement in performance mainly due to the size, morphology and distribution of particles that can act as bridges, facilitating the diffusion of water and aggressive ions. According to Pour-Ali et al. ${ }^{31}$ an increased particle size reduces the physical properties of the coating (barrier effect) and the morphology of coatings plays a fundamental role in the performance against corrosion. Thus, MCC may have intercepted the coating surface creating "bridges" for water and ions to reach the coating/metal interface, reducing the overall resistance of the coating system. When the particle size is reduced, as is case of $\mathrm{CNW}$, the protective effect is inverted since this reinforcement improved the barrier of the coating, thus increasing the system resistance.

Table 2 shows the $\mathrm{R}_{\mathrm{c}}, \mathrm{C}_{\mathrm{c}}, \mathrm{R}_{\mathrm{p}}$ or $\mathrm{Q}$ values for the polymeric coatings after 90 days of immersion in $3.5 \mathrm{wt} \%$ $\mathrm{NaCl}$ solution. After 90 days of immersion in $3.5 \mathrm{wt} \% \mathrm{NaCl}$ solution all coatings presented $\mathrm{C}_{\mathrm{c}}$ values below $10^{-9} \mathrm{~F} . \mathrm{cm}^{-2}$. Thus, the polymeric coatings may act to protect the metal substrate, because according to results obtained by Chen and $\mathrm{Liu}^{28}$, Mostafaei and Nasirpouri ${ }^{32}$, Sathiyanarayanan et al. ${ }^{33}$ when the values of $\mathrm{C}_{\mathrm{c}}<10^{-9} \mathrm{~F}_{\mathrm{cm}} \mathrm{cm}^{-2}$ the penetration of water molecules can be neglected and coatings act to protect the metal substrate. Polymeric coatings have many pores or defects that can be filled by corrosion products when exposed to corrosive medium after long periods, which increases the coating capacitance ${ }^{32,34}$.

The use of CNW PAni ES increases the Rp values and it is possible to obtain a polymer coating with superior anticorrosive properties compared to other coatings. According to Sathiyanarayanan et al. ${ }^{33} \mathrm{R}_{\mathrm{p}}$ values greater than $10^{7} \Omega . \mathrm{cm}^{2}$ provide efficient corrosion protection to carbon steel and this behavior was found for all coatings. Thus, although all analyzed coatings may be used for protection of steel, RE APS/CNW PAni ES - Zr coating acts more efficiently.

Figure 5 shows the polymeric coatings after $1000 \mathrm{~h}$ of exposure to salt spray. RE APS/CNW - Zr coating did not present blistering, RE APS - Zr coating presented blistering after $500 \mathrm{~h}$ of exposure and the other coatings presented blistering after $168 \mathrm{~h}$. Red and green corrosion products at the incision are observed for all samples. No differences were observed with respect to the corrosion products formed and the area of corrosion in the incision of the coatings in relation to the incorporation of the load. Similar behavior was observed by Asemani et al. ${ }^{35}$ by evaluating different epoxy-based polymer coatings using a zirconium conversion coating as a pretreatment of carbon steel.

The result of the subcutaneous migration test (Figure 6) indicates subcutaneous penetration of the electrolyte in the coating/metal substrate interface. After exposure for 1000 $\mathrm{h}$ to salt spray, all coatings showed a complete detachment, except RE APS - Zr, which showed partial detachment. In spite of the coating detachment, the metal substrate showed no corrosion products, demonstrating that the polymer coating with APS and the zirconium conversion coating pretreatment act to protect steel against corrosion. Similar behavior was observed Asemani et al. ${ }^{35}$ who not observed after $400 \mathrm{~h}$ of exposure to salt spray, the formation of corrosion products on the metal substrate after delamination of the coating.

The adhesion of coatings to a metal substrate is affected when exposure to these aggressive ions causes their permeation under the coating, facilitating the breaking of hydrogen bonds between the coating and the metal surface ${ }^{3,26,36}$. Thus, the use of the zirconium conversion coating on the metal substrate, in addition to improving the adhesion of the polymer coating to the metal substrate, acts as an additional layer of protection between the metal substrate and the polymer coating. It acts as a more effective barrier, making the cathodic reactions of the corrosive elements more resistant when it reaches the polymeric/metallic substrate interface ${ }^{37}$.

According to the literature ${ }^{37,38} \alpha-, \beta-, \gamma-\mathrm{FeOOH}, \alpha-\mathrm{Fe}_{2} \mathrm{O}_{3}$, $\mathrm{Fe}_{3} \mathrm{O}_{4}$, and amorphous oxyhydroxides are formed as reddishbrown corrosion iron. Figure 7 presents the results obtained by EDS upon mapping oxygen distribution in the samples incision submitted to exposure for $1000 \mathrm{~h}$ to salt spray. During exposure to salt spray an electrolyte layer is formed on the

Table 2. Parameters of the coating/substrate systems after 90 days of immersion in $3.5 \mathrm{wt} \% \mathrm{NaCl}$ solution.

\begin{tabular}{lccccc}
\hline Sample & $\mathrm{Rc}\left(\mathrm{M} \Omega \cdot \mathrm{cm}^{2}\right)$ & $\mathrm{Cc}\left(\mathrm{pF} . \mathrm{cm}^{-2}\right)$ & $\mathrm{Rp}\left(\mathrm{G} \Omega . \mathrm{cm}^{2}\right)$ & $\mathrm{Q}\left(\Omega^{-1} \mathrm{~s}^{\mathrm{n}^{*}}\right)$ & $\mathrm{n}$ \\
\hline RE APS - Zr & 1.35 & 85.4 & 7.01 & $154 \times 10-12$ & 0.717 \\
RE APS/MCC - Zr & 0.003 & 99.9 & 0.186 & $31.6 \times 10-12$ & 0.249 \\
RE APS/MCC PAni ES - Zr & 0.27 & 95.5 & 0.53 & $641 \times 10-12$ & 0.582 \\
RE APS/CNW - Zr & 13.2 & 20.7 & 0.9 & $219 \times 10-12$ & 0.852 \\
RE APS/CNW PAni ES - Zr & 0.249 & 67.5 & 27.3 & $117 \times 10-12$ & 0.808 \\
\hline
\end{tabular}

Where: Coating resistance $(\mathrm{Rc})$, coating capacitance $(\mathrm{Cc})$, polarization resistance $(\mathrm{Rp})$ and phase constant element $(\mathrm{Q})$ of polymer coatings.

* Ideal Capacitor $\mathrm{n}=1$, ideal resistor $\mathrm{n}=0$ and CPE $0<\mathrm{n}<1$ 

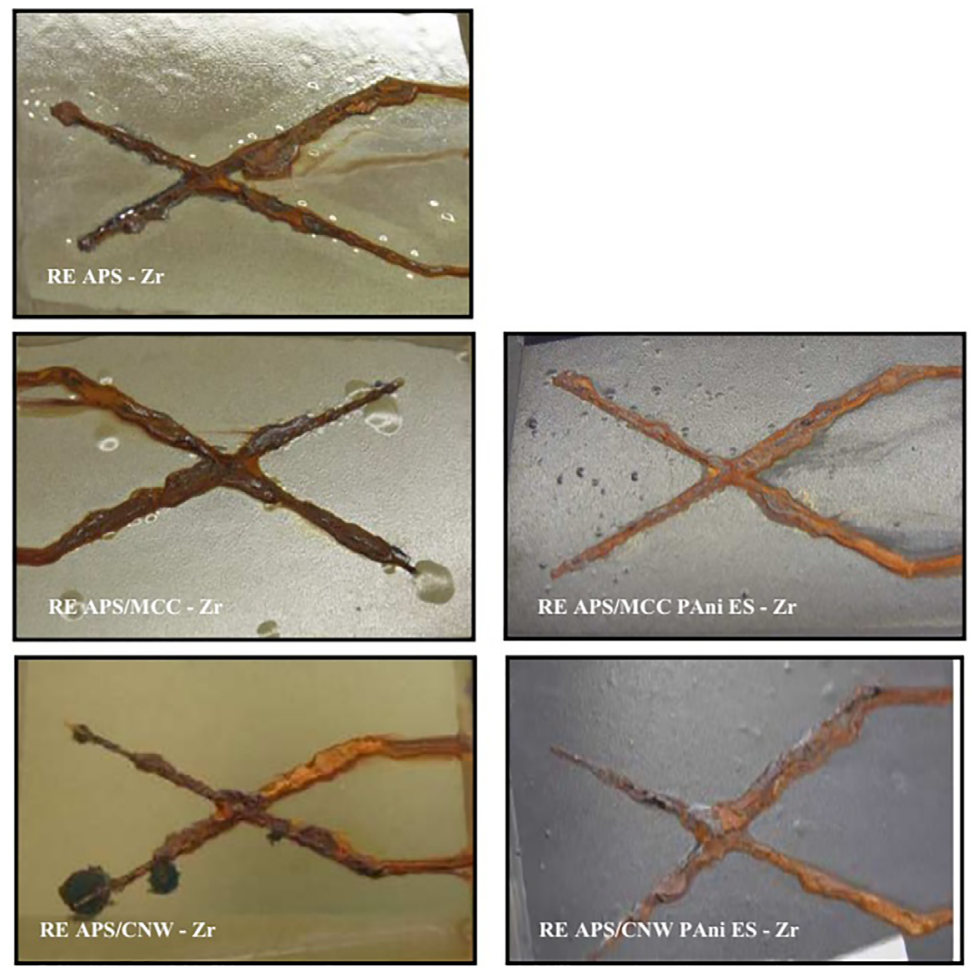

Figure 5. Appearance of swelling and corrosion products from the incision of the polymer coatings after $1000 \mathrm{~h}$ of exposure to salt spray.

RE APS - Zr

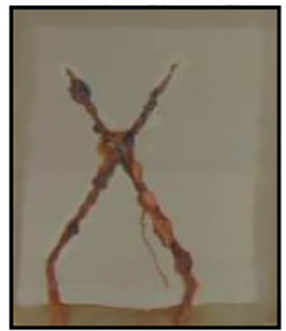

(B)

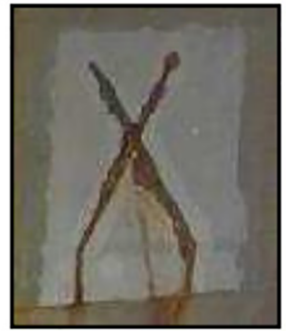

(c)

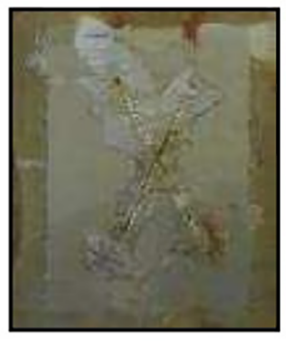

RE APS/MCC- Zr
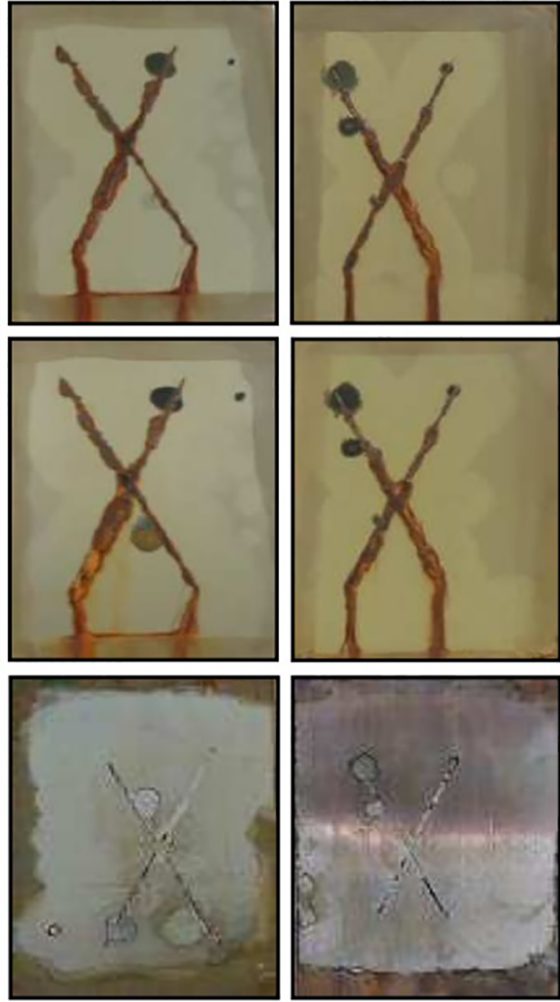

RE APS/MCC PAni ES$\mathrm{Zr}$
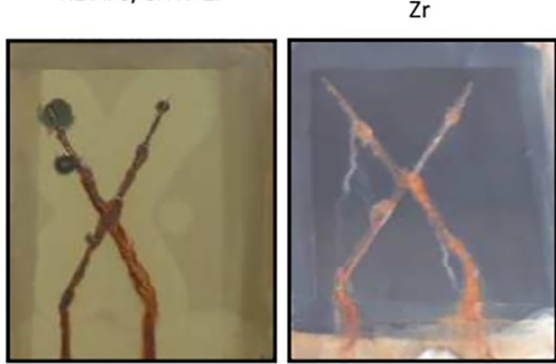

RE APS/CNW PAni ES-
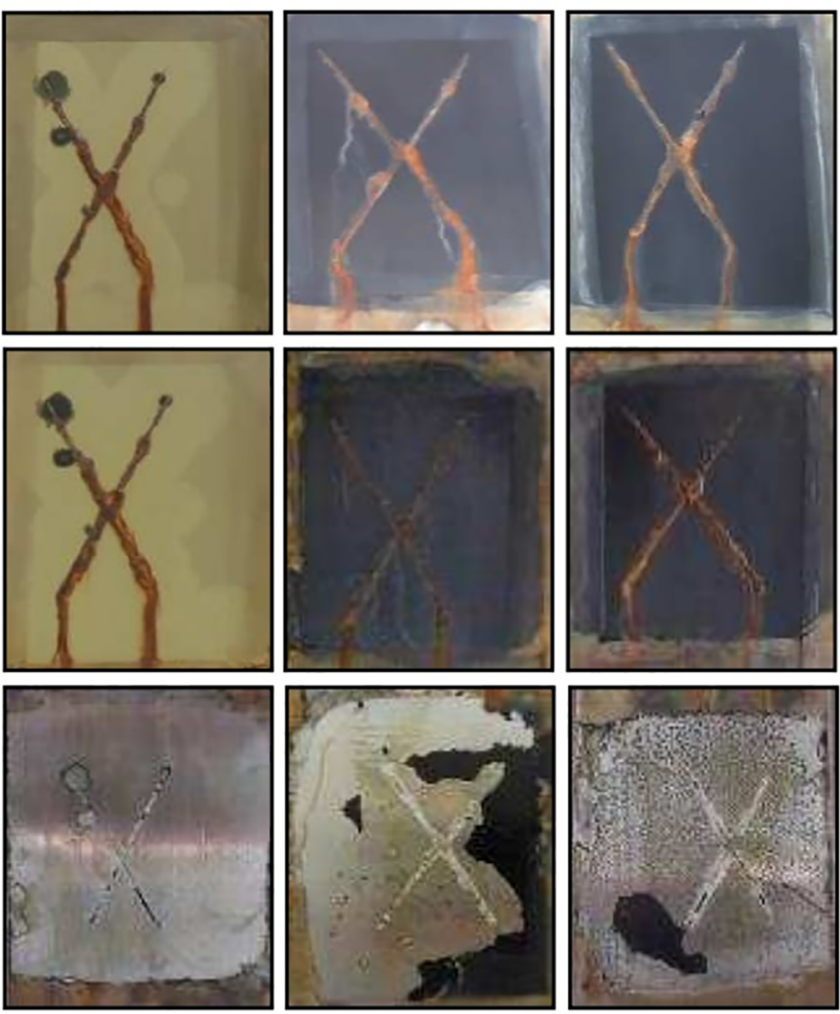

Figure 6. Appearance of the polymeric coatings after exposure to salt spray: (a) $500 \mathrm{~h}$, (b) $1000 \mathrm{~h}$ and (c) appearance after detachment of the coating upon analysis of subcutaneous migration after $1000 \mathrm{~h}$ of exposure to salt spray. 
polymeric coating surface and easy diffusion of oxygen and chloride ions causes accelerated corrosion where the coating is damaged. A similar behavior was observed by Prakash et al. ${ }^{39}$ in the evaluation of mild steel on the corrosion behavior in salt spray test using $3.5 \mathrm{wt} \% \mathrm{NaCl}$ solution.

Figure 8 shows the morphology of the corrosion products of the samples submitted to salt spray analysis after evaluating the subcutaneous migration to characterize the oxides present on the surface. Different morphologies of oxides were observed and the sample containing only MCC functionalized with PAni ES presented a structure formed with small pores. In Figure 8a, there were fine crystal (thin plates of flower-like structure) compact structures composed of $\gamma$-FeOOH. The morphology of the $\beta$-FeOOH phase, which is characterized by a morphology that reminds cotton balls and rosettes, was preferably formed in media with $\mathrm{Cl}^{-}$ions. The $\beta$-FeOOH phase accelerates the corrosion process while the $\gamma$-FeOOH phase is considered the primary factor of corrosion, but when these two phases coexist, $\beta$-FeOOH plays a major role in accelerating the corrosion rate. Figure $8 \mathrm{~b}$ shows the characteristic morphology of corrosion products formed under marine environment $\left(\mathrm{Cl}^{-}\right.$ions-containing environment) in the form of cigar-shaped crystals, typical of $\beta-\mathrm{FeOOH}$, which are characterized by accelerating the corrosion rate. A similar behavior was reported by De La Fuente et al. ${ }^{40}$, who evaluated the morphology of corrosion formed on mild steel after long-term atmospheric exposure (rural, urban, industrial, mild marine and severe marine), and by Prakash et al. ${ }^{39}$, who evaluated the corrosion behavior of mild steel in salt spray test using $3.5 \mathrm{wt} \% \mathrm{NaCl}$ solution.

The morphology presented in Figure $8 \mathrm{c}$ shows a typical corrosion product characterized by the reddish-brown aspect seen in Figure 6c with PAni ES coatings. This morphology results from the hydrolysis and oxidation of $\mathrm{Fe}^{2+}$ ions or the hydrolysis of $\mathrm{Fe}^{3+}$ ions with precipitation of $\mathrm{FeOOH}$. A similar behavior was observed by De La Fuente et al. ${ }^{40}$ and Pingitore et al. ${ }^{37}$ on the characterization of corrosion product layers on archaeological iron.

\section{Conclusions}
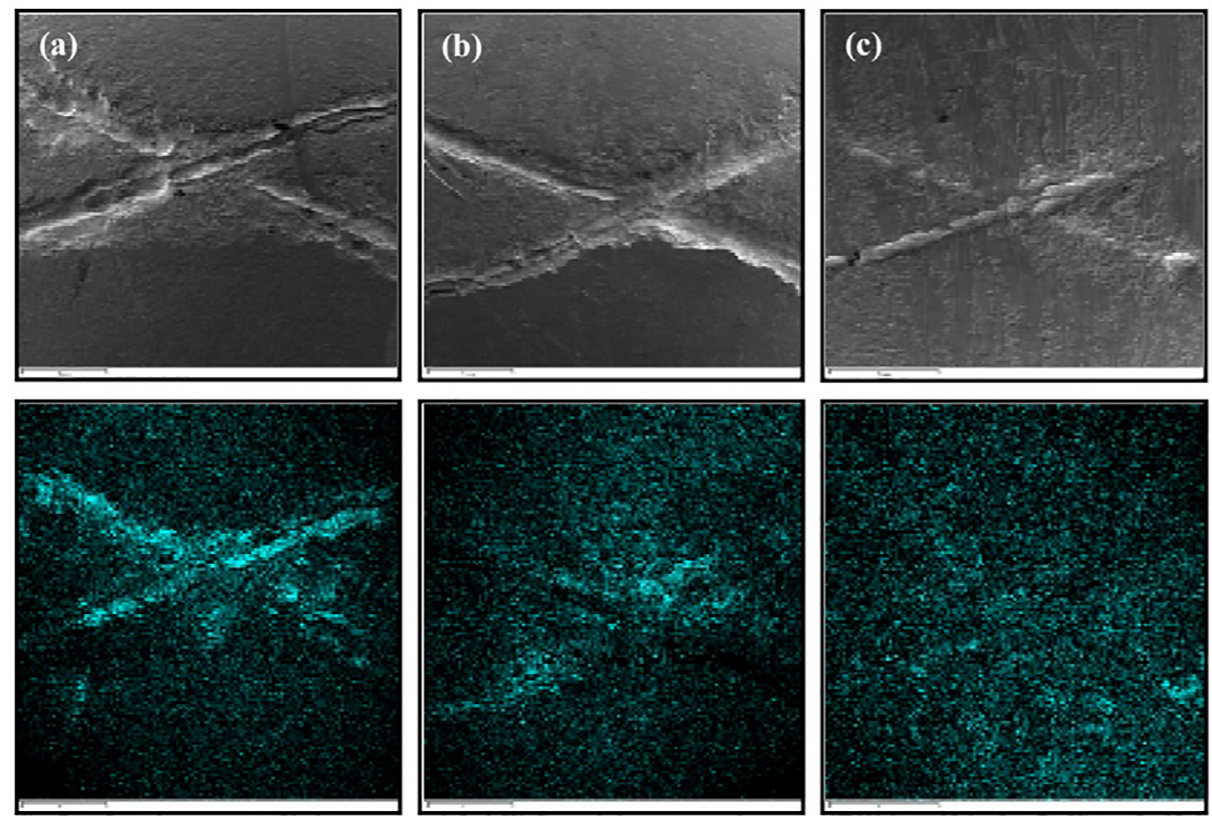

Figure 7. EDS analysis of the metal surface after subcutaneous migration test: (a) RE APS - Zr, (b) RE APS/MCC - Zr and (c) RE APS MCC PAni ES - Zr. Upper images: coating incision. Lower images: mapping distribution of elemental oxygen.
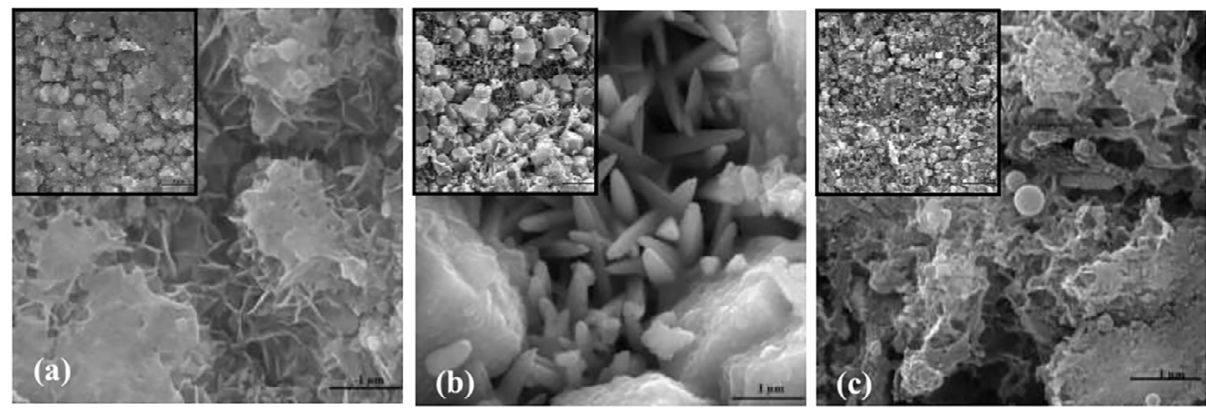

Figure 8. Micrographs of the surface after $1000 \mathrm{~h}$ exposure to salt spray (a) RE APS - Zr, (b) RE APS/MCC - Zr and (c) RE APS/MCC PAni ES - Zr. 
The synergistic effect of APS, cellulose and PAni ES in an epoxy coating on the corrosion protection mild steel pretreated with a zirconium conversion coating was investigated. After $1000 \mathrm{~h}$ of exposure to the salt spray the epoxy coatings presented corrosion products only at the sample incision. EIS results showed that no appropriate corrosion resistance of the coating in sodium chloride solution was obtained when cellulose ( $\mathrm{MCC}$ or $\mathrm{CNW}$ ) was used as reinforcement. However, a great increase in the corrosion resistance of the coatings was found for the coating reinforced with CNW functionalized with PAni ES, showing polarization resistance of $27.3 \mathrm{G} \Omega . \mathrm{cm}^{2}$. This result revealed a good combination of nanosized particles, which provided greater diffusion pathway to aggressive ions and water in comparison to microsized particles, and the electroactivity of the conducting polymer which allowed the formation of corrosion products of different morphologies.

\section{Acknowledgments}

The authors would like to express their gratitude to CNPq, CAPES, Department of Science and Technology - RS, Brazil and Recon Co. for the financial support.

\section{References}

1. Adhikari S, Unocic KA, Zhai Y, Frankel GS, Zimmerman J, Fristad W. Hexafluorozirconic acid based surface pretreatments: Characterization and performance assessment. Electrochimica Acta. 2011;56(4):1912-1924.

2. Lostak T, Krebs S, Maljusch A, Gothe T, Giza M, Kimpel M, et al. Formation and characterization of $\mathrm{Fe} 3+-/ \mathrm{Cu} 2+$-modified zirconium oxide conversion layers on zinc alloy coated steel sheets. Electrochimica Acta. 2013;112:14-23.

3. Ghanbari A, Attar MM. Surface free energy characterization and adhesion performance of mild steel treated based on zirconium conversion coating: A comparative study. Surface \& Coatings Technology. 2014;246:26-33.

4. Ramanathan E, Balasubramanian S. Comparative study on polyester epoxy powder coat and amide cured epoxy liquid paint over nano-zirconia treated mild steel. Progress in Organic Coatings. 2016;93:68-76.

5. Nikravesh B, Ramezanzadeh B, Sarabi AA, Kasiriha SM. Evaluation of the corrosion resistance of an epoxy-polyamide coating containing different ratios of micaceous iron oxide/Al pigments. Corrosion Science. 2011;53(4):1592-1603.

6. Olad A, Barati M, Behboudi S. Preparation of PANI/epoxy/Zn nanocomposite using $\mathrm{Zn}$ nanoparticles and epoxy resin as additives and investigation of its corrosion protection behavior on iron. Progress in Organic Coatings. 2012;74(1):221-227.

7. Casado UM, Aranguren MI, Marcovich NE. Preparation and characterization of conductive nanostructured particles based on polyaniline and cellulose nanofibers. Ultrasonics Sonochemistry. 2014;21(5):1641-1648.
8. Allahverdi A, Ehsani M, Janpour H, Ahmadi S. The effect of nanosilica on mechanical, thermal and morphological properties of epoxy coating. Progress in Organic Coatings. 2012;75(4):543-548

9. Jin FL, Park SJ. Thermal properties of epoxy resin/filler hybrid composites. Polymer Degradation and Stability. 2012;97(11):2148 2153 .

10. Jiang MY, Wu LK, Hu JM, Zhang JQ. Silane-incorporated epoxy coatings on aluminum alloy (AA2024). Part 1: Improved corrosion performance. Corrosion Science. 2015;92:118-126.

11. Chrusciel JJ, Lesniak E. Modification of epoxy resins with functional silanes, polysiloxanes, silsesquioxanes, silica and silicates. Progress in Polymer Science. 2015;41:67-121.

12. Kohl M, Kalendová A. Effect of polyaniline salts on the mechanical and corrosion propertiesof organic protective coatings. Progress in Organic Coatings. 2015;86:96-107.

13. Mathiazhagan A, Joseph R. Nanotechnology-A New Prospective in Organic Coating - Review. International Journal of Chemical Engineering and Applications. 2011;2(4):225-237.

14. Armelin E, Pla R, Liesa F, Ramis X, Iribarren JI, Alemán C. Corrosion protection with polyaniline and polypyrrole as anticorrosive additives for epoxy paint. Corrosion Science. 2008;50(3):721-728.

15. Jafarzadeh S, Claesson PM, Sundell PE, Tyrode E, Pan J. Active corrosion protection by conductive composites of polyaniline in a UV-cured polyester acrylate coating. Progress in Organic Coatings. 2016;90:154-162.

16. Jonoobi M, Mathew AP, Oksman K. Producing low-cost cellulose nanofiber from sludge as new source of raw materials. Industrial Crops and Products. 2012;40:232-238.

17. Pandey JK, Takagi H, Nakagaito NA, Saini D, Ahn SH. An overview on the cellulose based conducting composites. Composites Part B: Engineering. 2012;43(7):2822-2826.

18. Inai NH, Lewandowska AE, Ghita OR, Eichhorn SJ. Interfaces in polyethylene oxide modified cellulose nanocrystal - polyethylene matrix composites. Composites Science and Technology. 2018;154:128-135.

19. Ray D, Sain S. In situ processing of cellulose nanocomposites. Composites Part A: Applied Science and Manufacturing. 2016;83:19-37.

20. Mo ZL, Zhao ZL, Chen H, Niu GP, Shi HF. Heterogeneous preparation of cellulose-polyaniline conductive composites with cellulose activated by acids and its electrical properties. Carbohydrate Polymers. 2009;75(4):660-664.

21. Zheng Y, Wang W, Huang D, Wang A. Kapok fiber orientedpolyaniline nanofibers for efficient $\mathrm{Cr}(\mathrm{VI})$ removal. Chemical Engineering Journal. 2012;191:154-161.

22. Luong ND, Korhonen JT, Soininen AJ, Ruokolainen J, Johansson LS, Seppälä J. Processable polyaniline suspensions through in situ polymerization onto nanocellulose. European Polymer Journal. 2013;49(2):335-344.

23. Liu DY, Sui GX, Bhattacharyya D. Synthesis and characterisation of nanocellulose-based polyaniline conducting films. Composites Science and Technology. 2014;99:31-36. 
24. Borsoi C, Zattera AJ, Ferreira CA. Effect of cellulose nanowhiskers functionalization with polyaniline for epoxy coatings. Applied Surface Science. 2016;364:124-132.

25. Behzadnasab M, Mirabedini SM, Kabiri K, Jamali S. Corrosion performance of epoxy coatings containing silane treated $\mathrm{ZrO} 2$ nanoparticles on mild steel in $3.5 \% \mathrm{NaCl}$ solution. Corrosion Science. 2011;53(1):89-98.

26. Mohammadloo HE, Sarabia AA, Hosseini RM, Sarayloo M, Sameie H, Salimi R. A comprehensive study of the green hexafluorozirconic acid-based conversion coating. Progress in Organic Coatings. 2014;77(2):322-330.

27. Gonçalves GS, Baldissera AF, Rodrigues LF Jr., Martini EMA, Ferreira CA. Alkyd coatings containing polyanilines for corrosion protection of mild steel. Synthetic Metals. 2011;161(3-4):313-323.

28. Chen F, Liu P. Conducting Polyaniline Nanoparticles and Their Dispersion for Waterborne Corrosion Protection Coatings. ACS Applied Materials \& Interfaces. 2011;3(7):2694-2702.

29. Shi X, Nguyen TA, Suo Z, Liu Y, Avci R. Effect of nanoparticles on the anticorrosion and mechanical properties of epoxy coating. Surface \& Coatings Technology. 2009;204(3):237245 .

30. Conradi M, Kocijan A, Kek-Merl D, Zorko M, Verpoest I. Mechanical and anticorrosion properties of nanosilica-filled epoxy-resin composite coatings. Applied Surface Science. 2014;292:432-437.

31. Pour-Ali S, Dehghanian C, Kosari A. In situ synthesis of polyaniline-camphorsulfonate particles in an epoxy matrix for corrosion protection of mild steel in $\mathrm{NaCl}$ solution. Corrosion Science. 2014;85:204-214.
32. Mostafaei A, Nasirpouri F. Epoxy/polyaniline-ZnO nanorods hybrid nanocomposite coatings: Synthesis, characterization and corrosion protection performance of conducting paints. Progress in Organic Coatings. 2014;77(1):146-159.

33. Sathiyanarayanan S, Muthkrishnan S, Venkatachari G. Corrosion protection of steel by polyaniline blended coating. Electrochimica Acta. 2006;51(28):6313-6319.

34. Ji WG, Hu JM, Liu L, Zhang JQ, Cao CN. Improving the corrosion performance of epoxy coatings by chemical modification with silane monomers. Surface \& Coatings Technology. 2007;201(8):4789-4795.

35. Asemani HR, Ahmadi P, Sarabi AA, Mohammadloo H. Effect of zirconium conversion coating: Adhesion and anti-corrosion properties of epoxy organic coating containing zinc aluminum polyphosphate (ZAPP) pigment on carbon mild steel. Progress in Organic Coatings. 2016;94:18-27.

36. Ramezanzadeh B,Attar MM. An evaluation of the corrosion resistance and adhesion properties of an epoxy-nanocomposite on a hot-dip galvanized steel (HDG) treated by different kinds of conversion coatings. Surface \& Coatings Technology. 2011;205(19):4649-4657.

37. Pingitore G, Cerchiara T, Chidichimo G, Castriota M, Gattuso C, Marino D. Structural characterization of corrosion product layers on archaeological iron artifacts from Vigna Nuova, Crotone (Italy). Journal of Cultural Heritage. 2015;16(3):372-376.

38. Tamura $\mathrm{H}$. The role of rusts in corrosion and corrosion protection of iron and steel. Corrosion Science. 2008;50(7):1872-1883.

39. Prakash M, Shekhar S, Moon AP, Mondal K. Effect of machining configuration on the corrosion of mild steel. Journal of Materials Processing Technology. 2015;219:70-83.

40. De la Fuente D, Díaz I, Simancas J, Chico B, Morcillo M. Longterm atmospheric corrosion of mild steel. Corrosion Science. 2011;53(2):604-617. 